\title{
TU/e emonownen

\section{The stimulatory effect of notochordal cell-conditioned medium in a nucleus pulposus explant culture}

\section{Citation for published version (APA):}

De Vries, S. A. H., van Doeselaar, M., Meij, B. P., Tryfonidou, M. A., \& Ito, K. (2016). The stimulatory effect of notochordal cell-conditioned medium in a nucleus pulposus explant culture. Tissue engineering. Part $A, 22(1-2)$, 103-110. https://doi.org/10.1089/ten.tea.2015.0121

\section{Document license: \\ TAVERNE}

DOI:

10.1089/ten.tea.2015.0121

Document status and date:

Published: 01/01/2016

\section{Document Version:}

Publisher's PDF, also known as Version of Record (includes final page, issue and volume numbers)

\section{Please check the document version of this publication:}

- A submitted manuscript is the version of the article upon submission and before peer-review. There can be important differences between the submitted version and the official published version of record. People interested in the research are advised to contact the author for the final version of the publication, or visit the $\mathrm{DOI}$ to the publisher's website.

- The final author version and the galley proof are versions of the publication after peer review.

- The final published version features the final layout of the paper including the volume, issue and page numbers.

Link to publication

\section{General rights}

Copyright and moral rights for the publications made accessible in the public portal are retained by the authors and/or other copyright owners and it is a condition of accessing publications that users recognise and abide by the legal requirements associated with these rights.

- Users may download and print one copy of any publication from the public portal for the purpose of private study or research.

- You may not further distribute the material or use it for any profit-making activity or commercial gain

- You may freely distribute the URL identifying the publication in the public portal.

If the publication is distributed under the terms of Article 25fa of the Dutch Copyright Act, indicated by the "Taverne" license above, please follow below link for the End User Agreement:

www.tue.nl/taverne

Take down policy

If you believe that this document breaches copyright please contact us at:

openaccess@tue.nl

providing details and we will investigate your claim. 


\title{
The Stimulatory Effect of Notochordal Cell-Conditioned Medium in a Nucleus Pulposus Explant Culture
}

\author{
Stefan A.H. de Vries, MSc, ${ }^{1}$ Marina van Doeselaar, ${ }^{1}$ Björn P. Meij, DVM, PhD, ${ }^{2}$ \\ Marianna A. Tryfonidou, DVM, $\mathrm{PhD},{ }^{2}$ and Keita Ito, $\mathrm{MD}, \mathrm{ScD}^{1,3}$
}

\begin{abstract}
Objectives: Notochordal cell-conditioned medium (NCCM) has previously shown to have a stimulatory effect on nucleus pulposus cells (NPCs) and bone marrow stromal cells (BMSCs) in alginate and pellet cultures. These culture methods provide a different environment than the nucleus pulposus (NP) tissue, in which the NCCM ultimately should exert its effect. The objective of this study is to test whether NCCM stimulates NPCs within their native environment, and whether combined stimulation with NCCM and addition of BMSCs has a synergistic effect on extracellular matrix production.

Methods: Bovine NP tissue was cultured in an artificial annulus in base medium (BM), porcine NCCM, or BM supplemented with $1 \mu \mathrm{g} / \mathrm{mL}$ Link N. Furthermore, BM and NCCM samples were injected with $10^{6}$ BMSCs per NP sample. Samples were cultured for 4 weeks, and analyzed for biochemical contents (water, glycosaminoglycan [GAG], hydroxyproline, and DNA), gene expression (COL1A1, COL2A1, ACAN, and SOX9), and histology by Safranin O/Fast Green staining.

Results: Culture in NCCM resulted in increased proteoglycan content compared to day 0 and BM, similar to Link N. However, only minor differences in gene expression compared to day 0 were observed. Addition of BMSCs did not result in increased GAG content, and surprisingly, DNA content in BMSC-injected groups was not higher than in the other groups after 4 weeks of culture.

Discussion: This study shows that, indeed, NCCM is capable of stimulating NPC matrix production within the NP environment. The lack of increased DNA content in the BMSC-injected groups indicates that BMSCs have died over time. Identification of the bioactive factors in NCCM is crucial for further development of an NCCMbased treatment for intervertebral disc regeneration.
\end{abstract}

\section{Introduction}

$\mathbf{T}$ HE INTERVERTEBRAL DISC (IVD) separates vertebral bodies and provides flexibility to the spine. Its hydrated core, the nucleus pulposus (NP), is rich in negatively charged proteoglycans, which attract water. However, a fibrous ring, the annulus fibrosus (AF) constrains the NP and keeps it from swelling. Therefore, the NP is highly pressurized and plays a crucial role in the distribution of loads. With degeneration, nucleus pulposus cells (NPCs), responsible for production of the NP matrix components, such as proteoglycans and collagens, decrease in number and change their phenotype, resulting in a more catabolic behavior. ${ }^{1}$ Also, the gel-like NP changes toward a more fibrous tissue, where collagen type 2 is replaced by collagen type 1 .
The proteoglycan content and, therefore, the water content decreases, resulting in decreased IVD height. This changes the load distribution properties of the NP, causing more load to be exerted on the AF, which can further contribute to the degenerative process. IVD degeneration is associated with low back pain, ${ }^{2}$ and current treatment methods mostly aim at pain alleviation, but do not address the underlying mechanisms of IVD degeneration.

To replenish the decreasing number of NP cells and restore the IVD to a healthy state, bone marrow stromal cells (BMSCs) have been employed in regenerative treatment strategies ${ }^{3}$ and are currently being tested in clinical trials phase I/II (ClinicalTrials.gov: NCT01860417). BMSCs can either differentiate toward a chondrogenic phenotype and produce matrix themselves, or provide a trophic effect to the

\footnotetext{
${ }^{1}$ Orthopaedic Biomechanics, Department of Biomedical Engineering, and Institute for Complex Molecular Systems, Eindhoven University of Technology, Eindhoven, The Netherlands.

${ }^{2}$ Department of Clinical Sciences of Companion Animals, Faculty of Veterinary Medicine, Utrecht University, Utrecht, The Netherlands.

${ }^{3}$ Department of Orthopedics, University Medical Center Utrecht, Utrecht, The Netherlands.
} 
NPCs. ${ }^{4}$ Injection of BMSCs in the IVD has been shown to inhibit degenerative changes in a canine model. ${ }^{5,6}$ The majority of the BMSCs were present in the NP tissue, 12 weeks after injection and degeneration was arrested. However, addition of the BMSCs did not restore disc height. ${ }^{6}$ Therefore, to be able to restore the IVD to a healthy state, other or additional methods need to be investigated.

The use of notochordal cells (NCs) seems promising in IVD regeneration. NCs are large vacuolated cells present in the NP tissue of young individuals. It has been observed that their disappearance coincides with the onset of IVD degeneration. ${ }^{7}$ Furthermore, species retaining their NC population, such as pigs or certain dog breeds, keep a healthy IVD throughout the largest part of their lives. ${ }^{8}$ They may, therefore, play a role in maintaining a healthy IVD, and could be exploited to reverse the degenerative process.

Notochordal cell-conditioned medium (NCCM) obtained from NCs encapsulated in alginate beads, or directly from NC-rich NP tissue has been shown to have a stimulatory effect on NPCs as well as BMSCs in alginate beads and pellet cultures. Porcine NCCM stimulated matrix production by bovine NPCs and $\mathrm{BMSCs}^{9}$ and human $\mathrm{NPCs}^{10}$ in alginate bead cultures. Porcine NCCM also increased matrix production and chondrogenic gene expression in pellet cultures of human BMSCs. ${ }^{11,12}$ Furthermore, canine NCCM stimulated proliferation, ${ }^{13}$ proteoglycan production, ${ }^{13,14}$ and expression of genes associated with the chondrogenic phenotype by bovine NPCs. ${ }^{15}$ Furthermore, in a homologous canine model, NCCM increased proteoglycan production by NPCs and BMSCs, and anabolic gene expression by NPCs. 16

Altogether these results are promising; NCCM has only been tested on isolated cells in alginate bead and pellet cultures. Such culture methods provide a markedly different environment from the NP tissue, which could alter the cell's response to stimuli. For example, several studies demonstrated stimulation of isolated NPCs by osteogenic protein-1 (OP-1). ${ }^{17,18}$ However, in vivo the results were mixed. In the degeneration-induced rabbit model, which has a NP populated mostly by NCs, a stimulatory effect of OP-1 was observed. ${ }^{19,20}$ However, in a more relevant chondrodystrophied canine model of spontaneous disc degeneration, with NPC-rich NP, no stimulation after OP-1 injection was found. ${ }^{21}$ Furthermore, OP-1 has been used in human clinical trials, but these results were never released, making it likely that no large therapeutic effect was observed. $^{22,23}$ Finally, when OP-1 was eventually tested in moderately degenerated human NP tissue culture, only insufficient stimulatory effects were found. ${ }^{24}$ These findings indicate that the translation from cell to tissue scale is not necessarily a straightforward one, and testing an approach in a near in vivo situation will give a better idea of the in vivo feasibility. Similar to OP-1, NCCM, or its bioactive factors, should exert a stimulatory effect in the NP tissue. However, it is unknown whether NPCs within the NP tissue respond to NCCM stimulation, similar to isolated NPCs. Therefore, the aims of this study are 2-fold. First, to test the stimulatory effect of NCCM in an NP explant culture. Second, to test whether the addition of BMSCs, and hence combined stimulation of NP tissue with NCCM and BMSCs, can lead to a synergistic stimulatory effect on extracellular matrix synthesis.

\section{Materials and Methods}

\section{Porcine NCCM}

NC-rich NP tissue was harvested from the lumbar IVDs of 10 pigs (<3-month-old), obtained from a local abattoir. The IVDs were dissected and opened under aseptic conditions and the NP tissue was taken out and placed in highglucose Dulbecco's modified Eagle's medium (hgDMEM, Gibco; Invitrogen, Carlsbad, CA) $+1 \%$ penicillin/streptomycin (P/S; Lonza, Basel, Switzerland) with $30 \mathrm{~mL} / \mathrm{g}$ of tissue, as described previously. ${ }^{16}$ The porcine NPs were cultured for 4 days at $37^{\circ} \mathrm{C}, 5 \% \mathrm{O}_{2}$, and $5 \% \mathrm{CO}_{2}$. At the end of culture, the NP tissue was removed from the medium by filtration with a $70-\mu \mathrm{m}$ pore-size cell strainer, and medium of the different donors was pooled, two by two, to have enough medium for each repeat. The medium was stored at $-80^{\circ} \mathrm{C}$ until further use.

\section{Bovine BMSCs}

Bovine BMSCs were isolated by adherence to plastic from iliac bone marrow aspirates from five 4- to 12-monthold cows. They were expanded in hgDMEM supplemented with $1 \% \mathrm{P} / \mathrm{S}$ and $10 \%$ fetal calf serum (FCS Gold; PAA laboratories, Pasching, Austria) until subconfluence, before being stored at $\mathrm{P} 0$ in liquid nitrogen. A new vial of P0 BMSCs from a single donor was thawed and expanded up to P3 for each experiment.

\section{NP explant culture}

NP tissue explants were harvested from the caudal discs of five $\sim 2$-year-old cows obtained from a local abattoir. The IVDs were dissected, opened, and the NP explant was taken out aseptically using an $8 \mathrm{~mm}$ diameter biopsy punch and scalpel, rendering cylindrical explants with a diameter of $8 \mathrm{~mm}$ and a height of $\sim 5 \mathrm{~mm}$. Care was taken not to include AF tissue, or to scratch the endplate. The explants were placed in $15 \mathrm{kDa}$ molecular weight cut-off (MWCO) dialysis tubing (Spectra-Por, Rancho Dominguez, CA), and closed on both ends by custom-made closing rings. They were preshrunk for $100 \mathrm{~min}$ in a $30 \% \mathrm{w} / \mathrm{v}$ polyethylene glycol (20 kDa MW PEG; Sigma, Zwijndrecht, The Netherlands) solution in phosphate-buffered saline (Sigma), resulting in $\sim 20 \%$ shrinkage. Meanwhile, BMSCs were trypsinized and washed in fresh medium. One million BMSCs per NP explant were centrifuged, and the medium was aspirated, leaving behind $15-20 \mu \mathrm{L}$. The cell pellet was suspended in this $15-20 \mu \mathrm{L}$ medium by slowly pipetting up and down. The cell suspension was aspirated with a $27 \mathrm{G}$ needle and a $100-\mu \mathrm{L}$ Hamilton syringe (Da Vinci, Rotterdam, The Netherlands) and injected into the designated NP explants. The explants were then wrapped in $100 \mathrm{kDa}$ MWCO dialysis tubing and placed in a Dyneema fiber jacket (Varodem, Saint-Léger, Belgium), which was sewn closed tightly to constrain the NP explant and prevent it from swelling. Non-BMSC-injected explants were directly wrapped in the $100 \mathrm{kDa}$ membrane and placed in the fiber jacket after PEG shrinkage. This established method of culturing NP tissue has previously shown to maintain tissue integrity and cellular behavior. ${ }^{25}$

For each repeat, explants of one tail were cultured for 4 weeks in base medium (BM: hgDMEM $+1 \% \mathrm{P} / \mathrm{S}, 3 \% \mathrm{FCS}$ 
[Gibco], $50 \mu \mathrm{g} / \mathrm{mL}$ ascorbic acid-2-phosphate [Sigma], $40 \mu \mathrm{g} /$ $\mathrm{mL}$ L-proline [Sigma], and $100 \mu \mathrm{g} / \mathrm{mL}$ sodium pyruvate [Gibco]) with and without BMSC injection, NCCM (same supplements as BM, two donors pooled per repeat) with and without BMSC injection, or in BM supplemented with $1 \mu \mathrm{g} /$ $\mathrm{mL}$ Link N, used as a positive control. ${ }^{26,27}$ Explants were cultured at $37^{\circ} \mathrm{C}, 5 \% \mathrm{O}_{2}$, and $5 \% \mathrm{CO}_{2}$, and were given $6 \mathrm{~mL}$ medium. Medium was changed twice a week.

\section{Biochemical content}

At day 0 and 28, NP explants were weighed and cut in four equal parts. One-quarter was weighed before and after lyophilization. The water content was calculated as the percent difference between the wet weight and the dry weight of the sample. The dried samples were digested overnight at $60^{\circ} \mathrm{C}$ in papain digestion buffer $(100 \mathrm{mM}$ phosphate buffer, $5 \mathrm{mM}$ L-cystein, $5 \mathrm{mM}$ ethylene diamine tetraacetic acid, and $140 \mu \mathrm{g} / \mathrm{mL}$ papain, all from Sigma). The sample digests were assayed for glycosaminoglycan (GAG) content using a dimethylmethylene blue (DMMB) assay ${ }^{28}$ with shark cartilage chondroitin sulfate (Sigma) as a reference. DNA content was measured using the Qubit Quantification Platform (Invitrogen). Hydroxyproline, as a measure for collagen content, was measured using the Chloramine- $\mathrm{T}$ assay ${ }^{29}$ with a trans-4hydroxyproline (Sigma) reference. In addition, with every medium change a medium sample was collected, and assayed for GAG content with a modified DMMB protocol, to account for GAGs that could have leached out of the membrane during culture. For this assay, medium samples were mixed in a 1:1 ratio with two times concentrated digestion buffer. Also, standards were prepared in this mixture. Medium samples and standards were digested overnight, before continuing with the DMMB assay. For the NCCM-treated groups, the GAG in medium content was corrected for the GAG content in stock NCCM. GAG content in all medium samples was corrected for the FCS added to the medium. Water, GAG, DNA, and hydroxyproline contents were expressed as a percentage of the sample's wet weight.

\section{Histology}

One-quarter of each sample was fixed overnight in 3.7\% formalin at room temperature, and embedded in paraffin with a tissue processor (STP-120; Microm, Walldorf,
Germany). Sections with a thickness of $8 \mu \mathrm{m}$ were cut using a microtome (Leica, Wetzlar, Germany) and stained with Safranin O/Fast Green, to visualize proteoglycans and collagen and with Hematoxylin for cell nuclei. Pictures were taken with a brightfield microscope (Observer Z1; Carl Zeiss, Jena, Germany).

\section{Gene expression}

At day 0 and 28, two-quarters of the sample were snap frozen in liquid nitrogen and stored at $-80^{\circ} \mathrm{C}$ until RNA isolation. The frozen tissue pieces were disrupted with a MikroDismembrator (Sartorius, Goetingen, Germany) for $30 \mathrm{~s}$ at $2000 \mathrm{rpm}$, which was repeated if necessary. When the sample was pulverized, RNA was isolated using TRIzol, and purified using the Qiagen Mini Kit, with an on-column DNA digestion step. RNA quantity and purity was measured using a spectrophotometer (NC-1000; Isogen, de Meern, The Netherlands) and the absence of genomic DNA contamination in isolated RNA was verified with a minus-RT control reaction (iCycler; Bio-Rad, Veenendaal, The Netherlands). cDNA was synthesized using the VILO Kit (Invitrogen). Genes of interest were ACAN, COL1A1, COL2A1, and SOX9. Both reference genes (18S ribosomal rNA [18S]) and glyceraldehyde 3-phosphate dehydrogenase $(G A P D H)$, remained stable throughout the experimental conditions. Gene expression results are shown relative to GAPDH. Gene expression was investigated using real-time PCR (CFX384; Bio-Rad), and expression was calculated according to the $2^{-\Delta \Delta \mathrm{Ct}}$ method. Genes of interest and their corresponding primer pairs are summarized in Table 1.

\section{Statistics}

Statistics were performed with Statistical Package for Social Sciences (SPSS, version 21; IBM, Armonk, NY). Normality was tested using the Shapiro-Wilk test. A Kruskal-Wallis test was used, followed by a Mann-Whitney test with post hoc Bonferroni corrections. Statistical significance was accepted with $p$-values $<0.05$.

\section{Results}

\section{NCCM in a NP explant culture}

No differences were observed in water content between culture groups (Fig. 1a). The combined GAG content in the

Table 1. Primer Sequences for Target and Reference Genes Used in RT-QPCR Assays

\begin{tabular}{|c|c|c|c|}
\hline Gene & Accession number & Oligonucleotide sequence $\left(5^{\prime}-3^{\prime}\right)$ & Product size (bp) \\
\hline GAPDH & NM_001034034 & $\begin{array}{l}\text { FW: GGCGTGAACCACGAGAAGTATAA } \\
\text { RV: CCCTCCACGATGCCAAAGT }\end{array}$ & 119 \\
\hline COL1A1 & NM_001034039 & $\begin{array}{l}\text { FW: TGAGAGAGGGGTTGTTGGAC } \\
\text { RV: AGGTTCACCCTTCACACCTG }\end{array}$ & 142 \\
\hline COL2A1 & NM_001113224 & $\begin{array}{l}\text { FW: TGGCTGACCTGACCTGAC } \\
\text { RV: GGGCGTTTGACTCACTCC }\end{array}$ & 187 \\
\hline$A C A N$ & NM_173981 & $\begin{array}{l}\text { FW: CCAACGAAACCTATGACGTGTACT } \\
\text { RV: GCACTCGTTGGCTGCCTC }\end{array}$ & 107 \\
\hline SOX9 & AF278703 & $\begin{array}{l}\text { FW: ACGCCGAGCTCAGCAAGA } \\
\text { RV: CACGAACGGCCGCTTCT }\end{array}$ & 70 \\
\hline
\end{tabular}

GAPDH, glyceraldehyde 3-phosphate dehydrogenase; COL1A1, collagen type I alpha 1; COL2A1, collagen type II alpha 1; ACAN, aggrecan; SOX 9 , SRY (sex determining region Y)-box 9. 

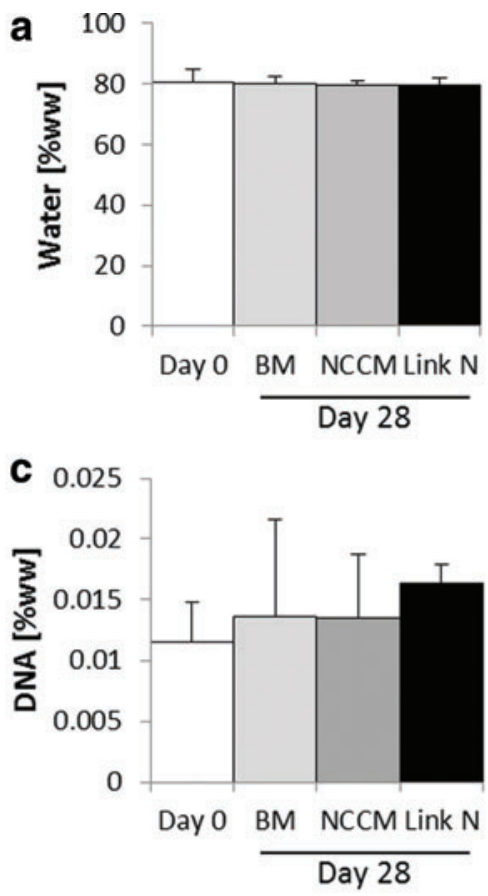

e

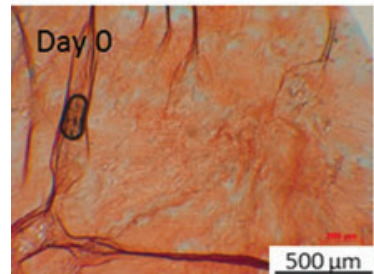

b
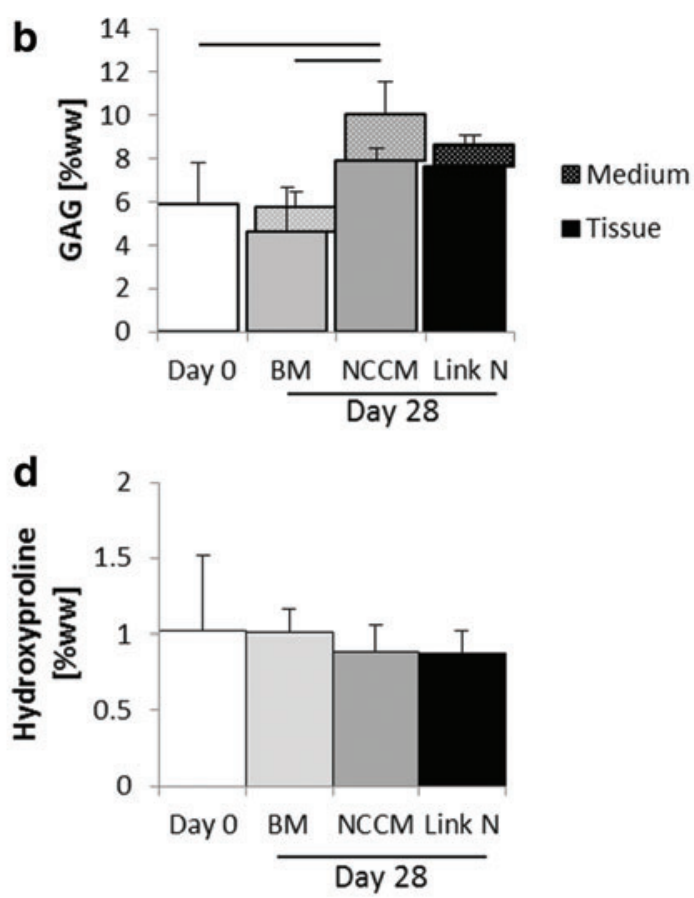

FIG. 1. (a) Water (b) GAG in the tissue sample and culture medium (c) DNA and (d) hydroxyproline content as a percentage of the tissues' wet weight. Statistics for GAG content were performed for the combined medium and tissue GAG content. Bars indicate $p<0.05$. (e) Safranin $\mathrm{O} /$ Fast Green staining for each of the culture groups. Link N, BM supplemented with $1 \mu \mathrm{g} / \mathrm{mL}$ Link N. $n=5$, results are represented as mean \pm SD. BM, base medium; NCCM, notochordal cell-conditioned medium; GAG, glycosaminoglycan; SD, standard deviation. Color images available online at www.liebertpub.com/tea

tissue sample and medium was significantly increased with NCCM compared to day 0 and BM (Fig. 1b). These results were verified with a histological Safranin O/Fast Green staining, showing a more intense red color in the NCCM group (Fig. 1e). There were no significant differences in the DNA (Fig. 1c) and hydroxyproline (Fig. 1d) content between culture groups.

No differences between culture groups in gene expression of COL1A1, COL2A1, ACAN, and SOX9 were found (Fig. 2). COLlAl increased in BM (4.9-fold) and Link $\mathrm{N}$ (3.7-fold) compared to day 0. COL2A1 decreased in BM (10-fold) compared to day 0 .

\section{BMSCs with NCCM in a NP explant culture}

No significant differences in water content were observed between groups (Fig. 3a). GAG content in the BMSCs and NCCM+BMSCs group was not significantly different from GAG content at day 0 and with NCCM alone (Fig. 3b). These results were verified by histological Safranin O/Fast
FIG. 2. Gene expression relative to $G A P D H$ and normalized to expression at day $0 . * p<0.05$ compared to expression at day $0 . n=4$ for BM, $n=5$ for NCCM and Link N. Results are represented as mean $\pm \mathrm{SD}$.

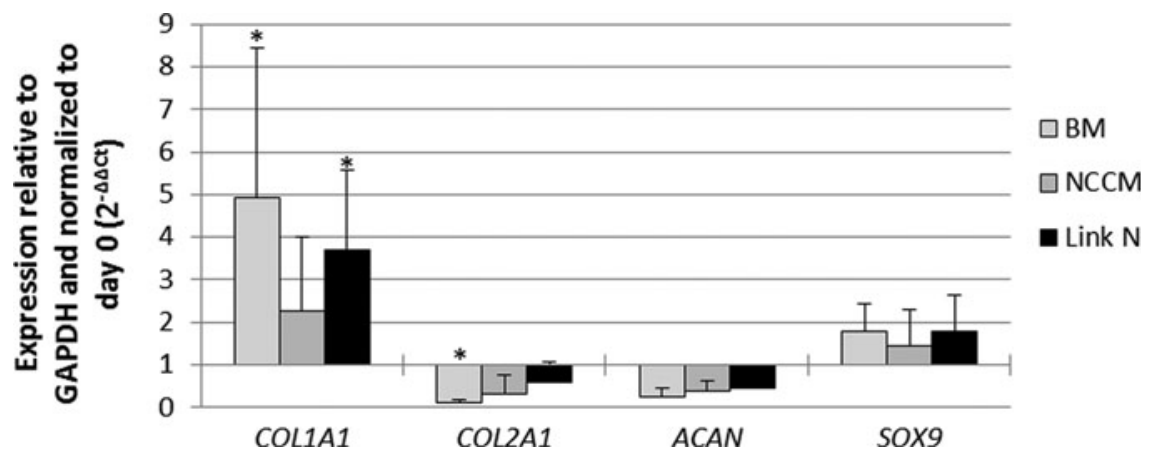



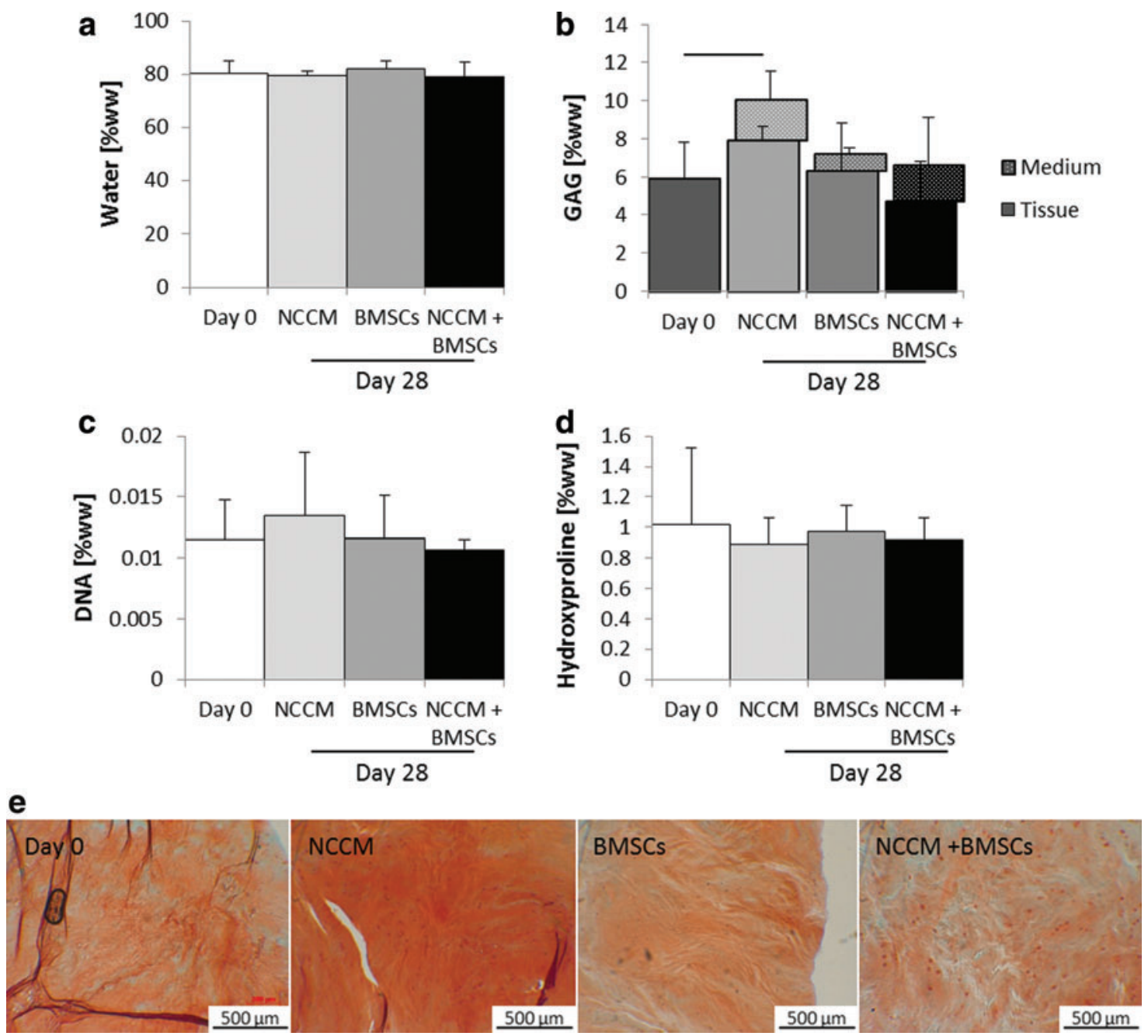

FIG. 3. (a) Water (b) GAG in the tissue sample and culture medium (c) DNA and (d) hydroxyproline content as a percentage of the tissues wet weight. Statistics for GAG content were performed for the combined medium and tissue GAG content. Bars indicate $p<0.05$. (e) Safranin O/Fast Green staining for each of the culture groups. BMSCs, $10^{6}$ bone marrow-derived stromal cells injected in the tissue; NCCM+BMSCs, $10^{6}$ bone marrow stromal cells injected in the nucleus pulposus tissue, cultured in NCCM. $n=5$, results are represented as mean \pm SD. Color images available online at www.liebertpub.com/tea

Green staining (Fig. 3e). Also, no significant differences in DNA (Fig. 3c) and hydroxyproline (Fig. 3d) content were found between culture groups.

No differences between culture groups were observed for COL1A1, COL2A1, ACAN, and SOX9 expression (Fig. 4). COL2A1 expression slightly decreased in the BMSC $(0.28 \times$ day 0$)$ and $\mathrm{NCCM}+\mathrm{BMSC}$ groups $(0.34 \times$ day 0$)$.

\section{Discussion}

This study verifies that NCCM provides a stimulatory effect on NPCs in their natural environment, that is, the NP tissue. This was demonstrated by increased proteoglycan content in the NCCM group compared to day 0 and BM, which was verified by histological Safranin O/Fast Green staining. Addition of BMSCs alone and addition of BMSCs

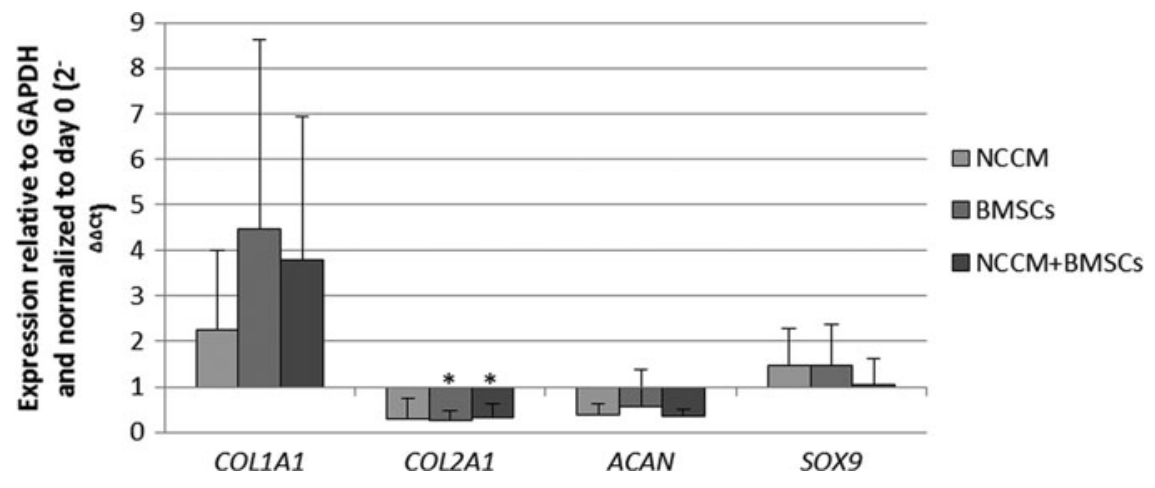

FIG. 4. Gene expression relative to $G A P D H$ and normalized to expression at day $0 .{ }^{*} p<0.05$ compared to expression at day $0 . n=4$ for BMSCs, $n=5$ for NCCM and NCCM+BMSCs. Results are represented as mean $\pm \mathrm{SD}$. 
combined with culture in NCCM did not lead to an upregulation of matrix production.

The stimulatory effect of NCCM has so far only been tested on NPCs in alginate bead and pellet cultures. $9,10,13-16$ In these studies, NCCM had stimulatory effects on matrix production, cell proliferation, and expression of genes associated with a healthy NP phenotype. However, alginate bead and pellet cultures provide a very different environment from the NP tissue. In alginate bead and pellet cultures there is initially no or hardly any matrix present, and different cell-matrix interactions could alter the cell's response to stimulation. For example, expression of COL1A1 and COL2A1 of NPCs increased when cultured in alginate beads suggesting that the cells are more active in producing matrix that has been lost during the isolation procedure. ${ }^{30}$ The question, therefore, remains whether the effect of NCCM would be biologically relevant, or even visible, in a NP tissue culture.

To test the feasibility of an NCCM-based treatment method for IVD regeneration, the stimulatory effect of NCCM needs to be verified on NPCs within their natural environment. Therefore, NP tissue samples were cultured in a fiber jacket, which constrains the tissue and keeps it from swelling. This method has previously shown to maintain stability of the tissue during at least 6 weeks of culture. ${ }^{25}$ Also, the current data indicates that stability of the NP sample and cellular behavior are largely maintained throughout the culture period.

The increased proteoglycan content in the NCCM group in the current study suggests that, indeed, NCCM stimulates NPCs within the NP tissue, which was verified by Safranin $\mathrm{O} /$ Fast Green staining. The anabolic effect of NCCM is not observed on the gene level, as no increase of $A C A N$ or COL2A1 was observed compared to day 0 or BM. The timing of harvest can be important to see changes in gene expression, and possibly, NCCM stimulation was desensitized after 4 weeks of culture and peaked at some point before analysis of gene expression, which could explain why the effect is not visible at the gene level anymore. Nonetheless, the finding that the end product, that is, GAG content significantly increased is more important than finding increased gene expression, as not all signals are translated into end products. Regardless of the treatment, GAGs were also released in the culture medium of all culture groups. Given that GAGs are also present in NCCM, the GAG content in the culture medium of the NCCM groups was corrected for the GAG content in the stock NCCM. This resulted in a positive value, which indicates that GAGs were produced by the cells rather than being incorporated from the medium itself. The latter is further corroborated by the absence of GAG accumulation at the border of the tissue, which was not observed in Safranin O/Fast Green staining.

It was previously found that aggrecan fragments were already present in mildly degenerated human NP tissue, ${ }^{31}$ which could have also been the case in the NP samples in this study, given that the NP explants were extracted from degenerated bovine IVDs. When small enough (i.e., smaller than the $100 \mathrm{kDa}$ pore size of the membrane) these fragments could diffuse out of the sample over time. Furthermore, harvesting the NP sample using a biopsy punch could disrupt the matrix network and add to further fragmentation. In an in vivo application of NCCM for IVD regeneration, that is, when NCCM's bioactive factors are injected in the
NP, small aggrecan fragments would likely remain in the disc, thereby still adding to the IVD's osmotic pressure.

Injection of BMSCs alone, as well as injection of BMSCs combined with culture in NCCM did not increase proteoglycan production in this study. Only $15-20 \mu \mathrm{L}$ of cell suspension was injected in the NP explant, without any sign of leakage. Also, quickly after injection, the sample was wrapped in the $100 \mathrm{kDa}$ membrane, which should not allow the BMSCs to migrate out. Therefore, an increased DNA content was expected in the BMSC-injected groups, but this was not the case, suggesting that the BMSCs have not survived the 4-week culture period. Recent studies support the idea that in in vitro chondrocyte-BMSC cocultures, BMSCs have a trophic effect on chondrocytes. In coculture without stimulants toward differentiation, the majority of the undifferentiated BMSCs disappeared over time, whereas only a small number of BMSCs differentiated. ${ }^{32,33}$ This could also explain a loss of BMSCs in the current study, and the lack of increase in $S O X 9$ expression, associated with differentiation toward the chondrogenic phenotype. Furthermore, hypoxic culture conditions and/or the NP environment itself may have been unfavorable for the survival of BMSCs. ${ }^{34}$

Interestingly, addition of BMSCs also did not have a trophic effect that resulted in increased matrix production. Previous studies investigating the trophic effects of BMSCs on NPCs and chondrocytes, ${ }^{4,32}$ found only a modest increase in matrix production in isolated cell cultures. Since the NP tissue is already rich in proteoglycans, it is possible that in the current study, addition of BMSCs did have a trophic effect, although not strong enough to result in a noticeable higher proteoglycan content. Furthermore, trophic effects of BMSCs on NPCs and chondrocytes were established by culture of isolated cells, and it is unknown whether this effect may hold in a tissue culture. The latter is in line with the in vivo findings, where BMSC transplantation alone arrested degeneration, but did not improve the disc height. ${ }^{6}$

Surprisingly, also the combined stimulation with injection of BMSCs and culture in NCCM did not promote GAG synthesis, although NCCM alone did. Possibly, if the BMSCs slowly disappeared over time, the NCCM's bioactive factors were used by a higher total number of cells in the NCCM+BMSC group, not providing a strong enough stimulation per cell to upregulate their matrix production. Alternatively, caspases activated in dying cells are known to be able to cleave proteins. ${ }^{35}$ This way, the apoptotic BMSCs in this study could have counteracted the stimulatory effect of NCCM.

Although the current results further underscore the promising role for $\mathrm{NC}$-secreted factors in IVD regeneration, the question still remains how this translates to the in vivo situation. Intradiscal injection of Link $\mathrm{N}$ in an annular puncture rabbit model of IVD degeneration resulted in partial restoration of disc height and expression of $A C A N$ and COL2A1. Also in this study, a positive, but not significant effect of Link $\mathrm{N}$ was observed on proteoglycan production. The effect of NCCM in nonoptimized form, however, was as strong as that of Link N. Furthermore, recent studies found that $\mathrm{NCCM}$ has a role in inhibiting neurite growth ${ }^{36}$ and blood vessel formation, ${ }^{37}$ which can together lead to innervation of the IVD and, therefore, cause back pain. These findings further add to the potential of NCCM in IVD regeneration. 
The NP explant culture method provides an environment that is more comparable to the in vivo situation than pellet or alginate bead cultures, but still differences exist that could give rise to a different cellular response to NCCM, such as a higher nutrient availability or the absence of dynamic loading. Furthermore, NCCM itself cannot be used directly for clinical application, as it would require a too high amount of fetal or young donor's NC-rich NP tissue, and likely, multiple injections would be needed to achieve an anabolic effect, which could affect IVD health. ${ }^{38}$ Identification of the active factors in NCCM will be required to overcome these problems. Recent studies have identified factors in NCCM, ${ }^{12,15}$ that could potentially be involved in its stimulatory activity, such as connective tissue growth factor. ${ }^{15}$

In conclusion, NCCM is capable of promoting matrix production in NP tissue, similar to alginate bead and pellet cultures. This raises further interest in the identification of the active factors secreted by NCs, and their application in IVD repair. In the current study, no stimulatory effect of addition of BMSCs to the NP tissue was observed. Although it is possible that the BMSCs need to differentiate to survive, the reason for their disappearance is uncertain. Therefore, we are unable to conclude on their stimulatory effect when injected in the NP tissue.

\section{Acknowledgments}

This work was supported by AOSpine International through an AOSpine Research Network grant (SRN2011_11). Marianna Tryfonidou was supported by the Dutch Arthritis Foundation (LLP22). Furthermore, the authors gratefully acknowledge Fackson Mwale for supplying them with Link N.

\section{Disclosure Statement}

No competing financial interests exist.

\section{References}

1. Zhao, C., Wang, L., Jiang, L., and Dai, L. The cell biology of intervertebral disc aging and degeneration. Ageing Res Rev 6, 247, 2007.

2. Battié, M.C., Videman, T., Levalahti, E., Gill, K., and Kaprio, J. Heritability of low back pain and the role of disc degeneration. Pain 131, 272, 2007.

3. Orozco, L., Soler, R., Morera, C., Alberca, M., Sánchez, A., and García-Sancho, J. Intervertebral disc repair by autologous mesenchymal bone marrow cells: a pilot study. Transplantation 92, 822, 2011.

4. Vadalà, G., Studer, R., Sowa, G., Spiezia, F., Iucu, C., Denaro, V., Gilbertson, L.G., and Kang, J.D. Coculture of bone marrow mesenchymal stem cells and nucleus pulposus cells modulate gene expression profile without cell fusion. Spine 33, 870, 2008.

5. Sakai, D., Mochida, J., Iwashina, T., Hiyama, A., Omi, H., Imai, M., Nakai, T., Ando, K., and Hotta, T. Regenerative effects of transplanting mesenchymal stem cells embedded in atelocollagen to the degenerated intervertebral disc. Biomaterials 27, 335, 2006.

6. Serigano, K., Sakai, D., Hiyama, A., Tamura, F., Tanaka, M., and Mochida, J. Effect of cell number on mesenchymal stem cell transplantation in a canine disc degeneration model. J Orthop Res 28, 1267, 2010.
7. Cappello, R., Bird, J., and Pfeiffer, D. Notochordal cell produce and assemble extracellular matrix in a distinct manner, which may be responsible for the maintenance of healthy nucleus pulposus. Spine 31, 873, 2006.

8. Smolders, L.A., Bergknut, N., Grinwis, G.C., Hagman, R., Lagerstedt, A.S., Hazewinkel, H.A., Tryfonidou, M.A., and Meij, B.P. Intervertebral disc degeneration in the dog. Part 2: chondrodystrophic and non-chondrodystrophic breeds. Vet J 195, 292, 2013.

9. Potier, E., de Vries, S.A.H., van Doeselaar, M., and Ito, K. Potential application of notochordal cells for intervertebral disc regeneration: an in vitro assessment. Eur Cells Mater 28, 68, 2014.

10. Abbott, RD, Purmessur, D., Monsey, R.D., and Iatridis, J.C. Regenerative potential of TGF $\beta 3$ + Dex and notochordal cell conditioned media on degenerated human intervertebral disc cells. J Orthop Res 30, 482, 2012.

11. Korecki, C.L., Taboas, J.M., Tuan, R.S., and Iatridis, J.C. Notochordal cell conditioned medium stimulates mesenchymal stem cell differentiation toward a young nucleus pulposus phenotype. Stem Cell Res Ther 1, 18, 2010.

12. Purmessur, D., Schek, R.M., Abbot, R.D., Ballif, B.A., Godburn, K.E., and Iatridis, J.C. Notochordal conditioned media from tissue increases proteoglycan accumulation and promotes a healthy nucleus pulposus phenotype in human mesenchymal stem cells. Arthritis Res Ther 13, 81, 2011.

13. Erwin, W.M., and Inman, R.D. Notochord cells regulate intervertebral disc chondrocyte proteoglycan production and proliferation. Spine 31, 1094, 2006.

14. Aguiar, D.J., Johnson, S.L., and Oegema, T.R. Notochordal cells interact with nucleus pulposus cells: regulation of proteoglycan synthesis. Exp Cell Res 246, 129, 1999.

15. Erwin, W.M., Ashman, K., O’Donnel, P., Inman, R. Nucleus pulposus notochord cells secrete connective tissue growth factor and up-regulate proteoglycan expression by intervertebral disc chondrocytes. Arthritis Rheum 54, 3859, 2006.

16. de Vries, S.A.H., Potier, E., van Doeselaar, M., Meij, B., Tryfonidou, M.A., and Ito, K. Conditioned medium derived from notochordal cell-rich nucleus pulposus tissue stimulates matrix production by canine nucleus pulposus cells and bone marrow-derived stromal cells. Tissue Eng 21, 1077, 2015.

17. Masuda, K., Takegami, K., An, H., Kumano, F., Chiba, K., Andersson, G.B.J., Schmid, T., and Thonar, E. Recombinant osteogenic protein-1 upregulates extracellular matrix metabolism by rabbit annulus fibrosus and nucleus pulposus cells cultured in alginate beads. J Orth Res 21, 922, 2003.

18. Imay, Y., Miyamoto, K., An, H.S., Thonar, J.M.A., Andersson, G.B.J., and Masuda, K. Recombinant human osteogenic protein-1 upregulates proteoglycan metabolism of human annulus fibrosus and nucleus pulposus cells. Spine 32, 1303, 2007.

19. Masuda, K., Imai, Y., Okuma, M., Muehleman, C., Nakagawa, K., Akeda, K., Thonar, E., Andersson, G., and An, H.S. Osteogenic protein-1 injection into a degenerated disc induces the restoration of disc height and structural changes in the rabbit annular puncture model. Spine 31, 742, 2006.

20. Miyamoto, K., Masuda, K., Kim, J.G., Inoue, N., Akeda, K., Andersson, G.B.J., and An, H.S. Intradiscal injections of osteogenic protein-1 restore the viscoelastic properties of degenerated intervertebral discs. Spine J 6, 692, 2006.

21. Willems, N., Bach, F.C., Plomp, S.G.M., van Rijen, M.H.P., Wolfswinkel, J., Grinwis, G.C.M., Bos, C., Strijkers, G.J., 
Dhert, W.J.A., Meij, B.P., Creemers, L.B., and Tryfonidou, M.A. Intradiscal application of rhBMP-7 does not induce regeneration in a canine model of spontaneous intervertebral disc degeneration. Arthritis Res 17, 137, 2015.

22. Zhang, Y., Chee, A., Thonar, E.J., and An, H.S. Intervertebral disk repair by protein, gene, or cell injection: a framework for rehabilitation-focused biologics in the spine. PM R 3, S88, 2011.

23. Masuda, K. Biological repair of the degenerated intervertebral disc by the injection of growth factors. Eur Spine J 17, S441, 2008.

24. van Dijk, B., Potier, E., van Dijk, M., Creemers, L., and Ito, $\mathrm{K}$. Does osteogenic protein 1 stimulate a regenerative effect in human degenerated nucleus pulposus tissue? J Tissue Eng Regen Med, 2015.

25. van Dijk, B.G.M., Potier, E., and Ito, K. Long-term culture of bovine nucleus pulposus explants in a native environment. Spine J 13, 454, 2013.

26. Mwale, F., Wang, H.T., Roughley, P., Antoniou, J., and Haglund, L. Link $N$ and mesenchymal stem cells can induce regeneration of the early degenerate intervertebral disc. Tissue Eng Part A 20, 2942, 2014.

27. Gawri, R., Antoniou, J., Ouellet, J., Awwad, W., Steffen, T., Roughley, P., Haglund, L., and Mwale, F. Best paper NASS 2013: Link-N can stimulate proteoglycan synthesis in the degenerated human intervertebral discs. Eur Cells Mater 26, 107, 2013.

28. Farndale, R.W., Sayers, C.A., and Barrett, A.J. A direct spectrophotometric microassay for sulfated glycosaminoglycans in cartilage cultures. Connect Tissue Res 9, 247, 1982.

29. Huszar, G., Maiocco, J., and Naftolin, F. Monitoring of collagen and collagen fragments in chromatography of protein mixtures. Anal Biochem 105, 424, 1980.

30. Wang, J.Y., Baer, A.E., Kraus, V.B., Huebner, J.L., and Setton, L.A. Differential collagen gene expression in intervertebral disc cells in alginate bead culture. 45th Annual Meeting, Orthopaedic Research Society, February 1-4, 1999, Anaheim, California.

31. Patel, K.P., Sandy, J.D., Akeda, K., Miyamoto, K., Chujo, T., An, H.S., and Masuda, K. Aggrecanases and aggrecanasegenerated fragments in the human intervertebral disc at early and advanced stages of disc degereration. Spine 32, 2596, 2007.

32. Wu, L., Leijten, J.H.C., Georgi, N., Post, J.N., Blitterswijk, C.A., and Karperien, M. Trophic effects of mesenchymal stem cells increase chondrocyte proliferation and matrix formation. Tissue Eng Part A 17, 1425, 2011.

33. Wu, L., Leijten, J.C.H., Georgi, N., Post, J.N., Blitterswijk, C.A., and Karperien, M. Trophic effects of mesenchymal stem cells in chondrocyte co-cultures are independent of culture conditions and cell sources. Tissue Eng Part A 18, 1542, 2012.

34. Wuertz, K., Godburn, K., Neidlinger-Wilke, C., Urban, J., and Iatridis, J.C. Behavior of mesenchymal stem cells in the chemical microenvironment of the intervertebral disc. Spine 33, 1843, 2008.

35. Elmore, S. Apoptosis: a review of programmed cell death. Toxicol Pathol 35, 495, 2007.

36. Purmessur, D., Cornejo, M.C., Cho, S.K., Roughley, P.J., Linhardt, R.J., Hecht, A.C., and Iatridis, J.C. Intact glycosaminoglycans from intervertebral disc-derived notochordal cell-conditioned media inhibit neurite growth while maintaining neuronal cell viability. Spine J 15, 1060, 2015.

37. Cornejo, M.C., Cho, S.K., Giannarelli, C., Iatridis, J.C., and Purmessur, D. Soluble factors from the notochordal-rich intervertebral disc inhibit endothelial cell invasion and vessel formation in the presence and absence of proinflammatory cytokines. Osteoarthr Cartil 23, 487, 2015.

38. Korecki, C.L., Costi, J.J., and Iatridis, J.C. Needle puncture injury affects intervertebral disc mechanics and biology in an organ culture model. Spine 33, 235, 2008.

Address correspondence to: Keita Ito, $M D, S c D$ Orthopaedic Biomechanics, Department of Biomedical Engineering

Institute for Complex Molecular Systems Eindhoven University of Technology P.O. Box 513 $5600 \mathrm{MB}$ Eindhoven The Netherlands

E-mail:k.ito@tue.nl

Received: March 11, 2015 Accepted: September 22, 2015

Online Publication Date: November 3, 2015 